\title{
Electrical properties of polyethylene composite films filled with nickel powder and short carbon fiber hybrid filler
}

\author{
V. S. Mironov, Seong Yun Kim and Min Park* \\ Soft Innovative Materials Research Center, Korea Institute of Science and Technology, Wanju 565-905, Korea
}

\section{Article Info}

Received 14 February 2013

Accepted 10 March 2013

*Corresponding Author

E-mail: minpark@kist.re.kr

Tel: $+82-2-958-5334$

\section{Open Access}

DOI: http://dx.doi.org/

10.5714/CL.2013.14.2.105

This is an Open Access article distributed under the terms of the Creative Commons Attribution Non-Commercial License (http://creativecommons.org/licenses/ by-nc/3.0/) which permits unrestricted non-commercial use, distribution, and reproduction in any medium, provided the original work is properly cited.

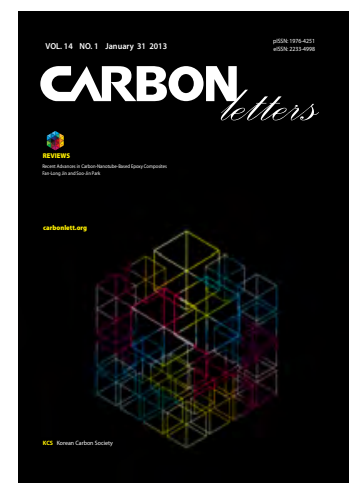

http://carbonlett.org

pISSN: 1976-4251

elSSN: 2233-4998

Copyright $\odot$ Korean Carbon Society

\begin{abstract}
Effects of the amount of nickel powder (Ni) in Ni-carbon fiber (CF) hybrid filler systems on the conductivity(or resistivity) and thermal coefficient of resistance (TCR) of filled high density polyethylene were studied. Increases of the resistivity and TCR with increasing Ni concentration at a given hybrid filler content were observed. Using the fiber contact model, we showed that the main role of $\mathrm{Ni}$ in the hybrid filler system is to decrease the interfiber contact resistance when Ni concentration is less than the threshold point. The formation of structural defects leading to reduced reinforcing effect resulted in both a reduction of strength and an increase of the coefficient of thermal expansion in the composite film; these changes are responsible for the increases of both resistivity and TCR with increasing Ni concentration in the hybrid filler system.
\end{abstract}

Key words: conductive polymer composites, hybrid filler, fiber contact model, contact resistance

\section{Introduction}

Conductive polymer composites (CPCs) have been finding more and more industrial as well as strategic applications since the 1950s in the fields of electromagnetic interference (EMI) shielding [1-3], electrostatic discharge dissipation [4,5], pressure-sensing [6-8], selfheating $[9,10]$ and electrode systems $[11,12]$.

Carbon fibers (CFs) in continuous form have for decades been used in general to fabricate lightweight advanced composite materials like CF reinforced plastics (CFRPs) $[13,14]$. Discontinuous CFs such as short, chopped or milled CFs are also widely employed to yield various CPCs though high speed processing methods including injection molding. Because the performance enhancement in CPCs is largely dependent on the aspect ratio of the incorporated filler, discontinuous $\mathrm{CFs}$ with higher aspect ratio are desirable as fillers for CPCs. It is known that the high cost of CFs has limited wider use of CFRPs in many demanding applications. One promising way to reduce the cost of CF reinforced CPCs is to use a hybrid filler, in which some part of the CF is replaced with cheaper powdered filler like carbon black $[15,16]$. The use of conductive powder in combination with CFs is expected to achieve cost reduction or even balanced properties of the resulting composites. Indeed, the use of a ferromagnetic metal powder like Ni has been found to increase the magnetic permeability of polymer composites [17,18]. As a consequence, the resulting CPCs may possess enhanced EMI shielding effectiveness, which is a critical property for EMI shielding materials [19].

In this connection the purpose of the present paper is to elucidate the effects of nickel powder $(\mathrm{Ni})$ on the electrical conductivity(or resistivity) and thermal coefficient of resistance (TCR) of polyethylene film filled with short CF-Ni hybrid filler. 


\section{Experimental}

\subsection{Materials}

High density polyethylene (HDPE, Grade M850, MI $=4.7 \mathrm{~g}$ $/ 10 \mathrm{~min}$ ) in powder form from Yuhwa Hiden Co. (Korea) was used as the polymer binder. The average size (diameter) of the utilized polymer particles was less than $0.2 \mathrm{~mm}$. The chopped (length of $1.5 \mathrm{~mm}$ ) CF sized with epoxy (Grade TZ-307) from Tae Kwang Co. (Korea) and Ni (Type 255) from INCO (Canada) were employed as filler materials. Ni particles have nearly spherical shape, with average diameter of about $3 \mathrm{~mm}$.

\subsection{Preparation of samples}

CF/HDPE composite films were prepared using so-called electron-ion technology in accordance with the scheme described previously [20]. Flat steel plates $(200 \times 200 \times 3 \mathrm{~mm})$ with Teflon coating were used as an intermediate technological substrate. A thin polymer binder layer, called a sublayer (thickness of 80-100 $\mu \mathrm{m}$ ), was applied to the substrate using a vibrospreading apparatus; resulting specimen became molten in an oven at a temperature of $453 \mathrm{~K}$ for $10 \mathrm{~min}$. Then, chopped $\mathrm{CFs}$ were subsequently deposited onto a molten polymer sublayer using a special fiber-feeding apparatus with brush screws under high intensity DC electric field at a field strength of about $3 \mathrm{kV} / \mathrm{cm}$. The density of the formed aligned CF layer was about $25-30 \mathrm{~g} / \mathrm{m}^{2}$. Ni powder was added to previously deposited CF using the vibrospreading apparatus. Ni concentration in the hybrid filler system was in the range of 0 to $20 \mathrm{wt} \%$. Total filler content in all fabricated composite films was fixed at $20 \mathrm{wt} \%$. The composite film was obtained by compression molding (Tetrahedron Press, USA) at $453 \mathrm{~K}$ under pressure of $0.3 \mathrm{MPa}$ for 2 min with preheating for $3 \mathrm{~min}$ and cooling on the substrate in ambient condition. In the compression molding, anti-adhesion Teflon film was used for easy demolding. The thickness of the composite films was varied from 140 to $545 \mu \mathrm{m}$.

\subsection{Testing of samples}

The volume resistivity of the conductive film samples (length 140-150 mm, width $20 \mathrm{~mm}$ ) was evaluated using the 4-probe method according to ASTM D 991-89. DC voltage current standard (Yokogawa Electric Works Ltd., Japan), a 6512 electrometer (Keithly, USA) with very high internal resistance, and a 3466A digital multimeter (Hewlett-Packard, USA) were used as the stabilized power supply, voltmeter and milliammeter, respectively. This experimental setup ensures highly accurate determination of the volume resistivity for electrically conductive materials. Temperature dependence of the resistivity of composite films was measured in the temperature range of 295-353 K at a heating rate of $0.5 \mathrm{~K} / \mathrm{min}$. The resistivity and TCR were averaged out from the values for 4-6 samples. Optical microscopic analysis was carried out using a polarized microscope (Optiphot 2-Pol, Nikon, Japan). The tensile strength of the films was determined on standard test specimens according to ASTM D 638-89 using an MTS 45/G Testing Machine (MTS, USA) at the deformation rate of $10 \mathrm{~mm} / \mathrm{min}$.

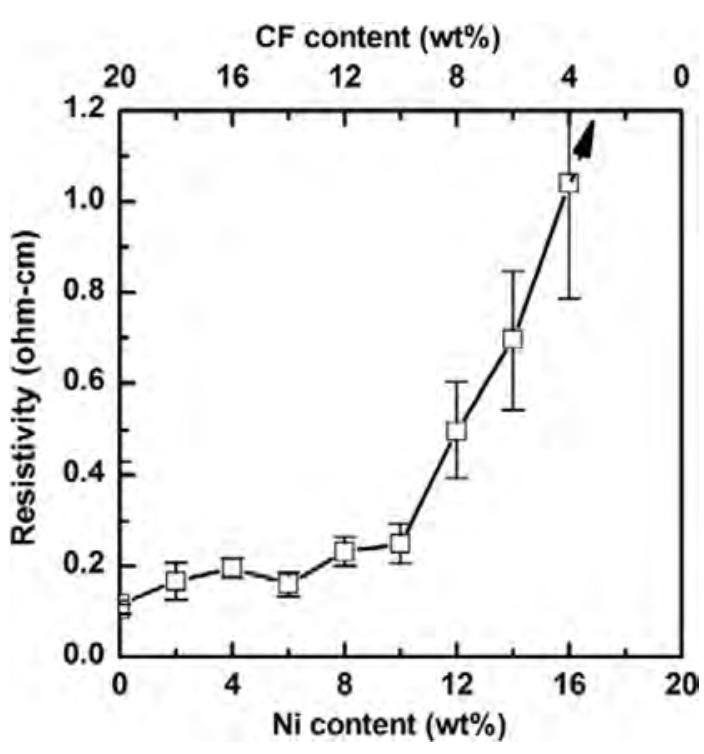

Fig. 1. Dependence of volume resistivity of composite films on nicke powder (Ni) concentration at a given hybrid filler content of $20 \mathrm{wt} \%$. CF: carbon fiber.

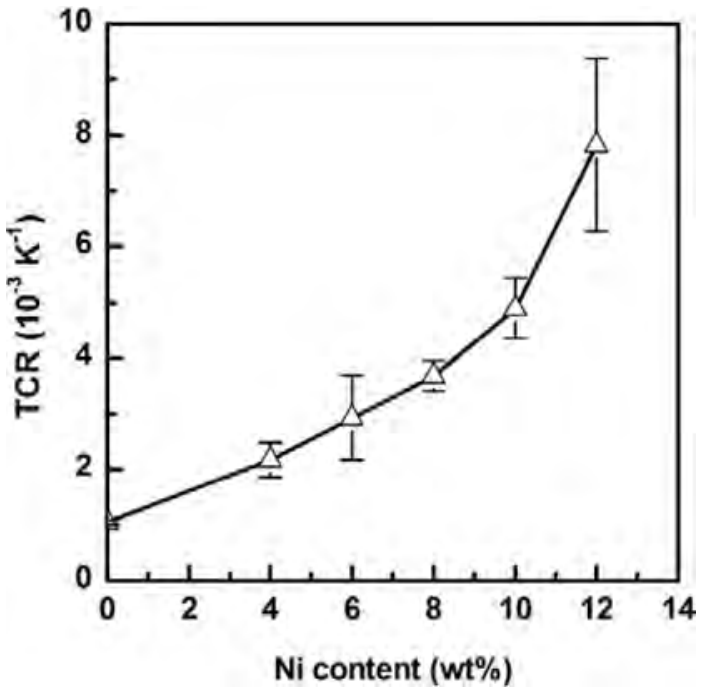

Fig. 2. Dependence of thermal coefficient of resistance (TCR) of composite films on nickel powder (Ni) concentration at a given hybrid filler content of $20 \mathrm{wt} \%$.

\section{Results and Discussion}

The dependence of the volume resistivity of the composite film on the $\mathrm{Ni}$ concentration at a given hybrid filler content of $20 \mathrm{wt} \%$ is presented in Fig. 1. It can be seen that the resistivity of the composite film increased from 0.11 to $0.25 \mathrm{~W} \cdot \mathrm{cm}$ with increasing Ni concentration up to $10 \mathrm{wt} \%$ in the hybrid filler. Increasing the $\mathrm{Ni}$ concentration to $16 \mathrm{wt} \%$ causes a rapid increase of the resistivity of about 4 times (up to $1.04 \Omega \cdot \mathrm{cm}$ ). At an Ni concentration of $20 \mathrm{wt} \%$, the resistivity of the composite film increased more than $10^{9} \Omega \cdot \mathrm{cm}$, implying that the composite film is nearly insulating. As with the resistivity, one of the significant characteristics of CPC, such as TCR, is also found to increase 
Table 1. Electrical properties of composite films filled with hybrid filler and CF only

\begin{tabular}{ccc} 
Composite film & $\begin{array}{c}\text { Resistivity, } \rho \\
(\Omega \cdot \mathrm{cm})\end{array}$ & $\begin{array}{c}\text { TCR } \\
\left(10^{-3} \mathrm{~K}^{-1}\right)\end{array}$ \\
\hline$(10 \mathrm{CF}+10 \mathrm{Ni}) / 80 \mathrm{HDPE}$ & 0.25 & 4.89 \\
$(5 \mathrm{CF}+15 \mathrm{Ni}) / 80 \mathrm{HDPE}$ & 0.87 & - \\
$5 \mathrm{CF} / 95 \mathrm{HDPE}$ & 2.7 & - \\
$10 \mathrm{CF} / 90 \mathrm{HDPE}$ & 0.28 & 3.08 \\
$20 \mathrm{CF} / 80 \mathrm{HDPE}$ & 0.11 & 1.05 \\
\hline
\end{tabular}

TCR: thermal coefficient of resistance, CF: carbon fiber, Ni: nickel powder, HDPE: high density polyethylene.

with increasing $\mathrm{Ni}$ concentration in the hybrid filler as can be seen in Fig. 2.

The electrical properties of the composite films filled with hybrid filler and with CF only are presented in Table 1 for comparison. From Table 1, the difference in the resistivity of the composite films filled with hybrid filler and those with $\mathrm{CF}$ only is pronounced when the CF content decreased from 10 to $5 \mathrm{wt} \%$. The reduction of the CF concentration at a given hybrid filler content leads to an increase of the Ni concentration. According to the literature [17], the critical concentration of powdered Ni in thermoplastics, at which a sharp drop of the resistivity occurs, lies in the range of $5-20 \mathrm{vol} \%$ (or about $30-65 \mathrm{wt} \%)$, depending on the shape or the aspect ratio of the Ni particles. Therefore, the amount of $\mathrm{Ni}$ in the hybrid filler is sufficiently low to create a continuous conductive network in the bulk polymer matrix. This is well confirmed by microphotographs of the composite film filled with CF only (Fig. $3 \mathrm{a}$ ) and those filled with hybrid filler (Fig. 3b). The composite film filled with hybrid filler shows that Ni particles are distributed in the interfiber space in the form of either separated particles or agglomerates. Obviously, the connectivity of the $\mathrm{CF}$ conductive network would be reduced when $\mathrm{Ni}$ powder is introduced to replace CF. From this aspect, it is possible to assume that the role of $\mathrm{Ni}$ powder is to improve the electrical contact between the fibers. This is also equivalent to an increase of the extent of interfiber contacts in the CF conductive network.

In order to prove the claims made above, we use the fiber contact model [21] to consider the effect of fiber-fiber contact we were able to determine that the model is in good agreement with the experimental data. According to this model, the electrical resistivity of the discontinuous fiber polymer composite in the longitudinal direction, for example, is given by the following formula:

$$
\rho_{C}=\frac{\pi d^{2} \rho_{F} X}{4 \phi d_{C} l \cos ^{2} \theta}
$$

where $d$ and $l$ are the diameter and the length of the discontinuous fibers, respectively; $\rho_{F}$ is the resistivity of fibers; $\phi$ is the volume fraction of the fibers participating in strings; $d_{C}$ is the diameter of the contact circle; and $\theta$ is an angle of the orientation of fibers with respect to each other. The coefficient in Eq. (1):

$$
X=1 /(0.59+0.15 m)
$$

(a)

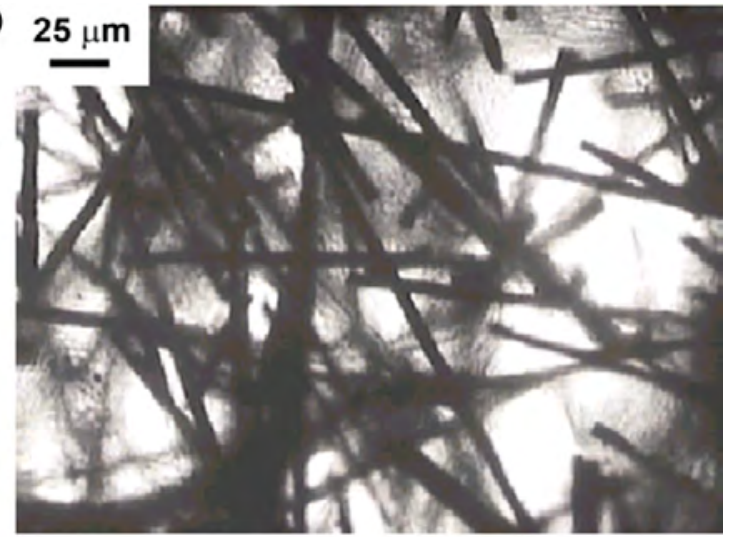

(b)

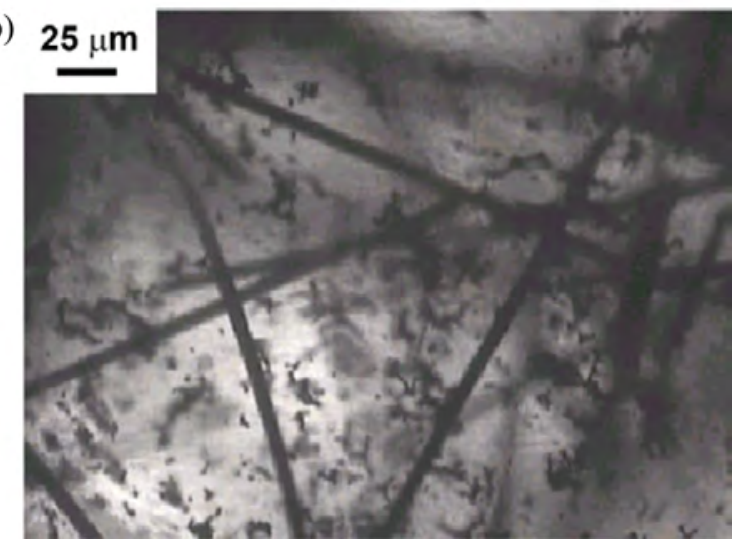

Fig. 3. Optical micrographs of composite film at filler content of 20 wt $\%$ : (a) carbon fiber (CF) only and (b) hybrid filler consisting of $10 \mathrm{wt} \%$ $\mathrm{CF}$ and $10 \mathrm{wt} \%$ nickel powder.

is a parameter that depends on the number of contacts, $\mathrm{m}$, for each fiber. The minimum number of contacts is $m=2$; the maximum number of contacts $m_{\max }=15$ is assumed to occur at fiber volume content $\phi_{m}$, which is beyond the critical concentration of fibers when all fibers do participate in strings. The critical concentration of fibers was assumed to be $f_{m}=$ 0.0711 . For other fiber content $f<f_{m}$, the number of contacts $\mathrm{m}_{\mathrm{f}}$ can be found using:

$$
m_{\phi}=m_{\max }\left(\phi / \phi_{m}\right)
$$

Assuming unknown parameters $d_{C}$ and $\theta$ are constant, the extent of the reduction of both the number of contacts and the resistivity of the films can be estimated; the final value is attributed to the decrease of CF concentration at a given hybrid filler content. Calculated values are given in Table 2.

The comparison of calculated and experimental results shows that the calculated value of 3.60 is relatively close to the experimental value of 2.55 only for the ratio $\rho_{10} / \rho_{20}$. In other cases, calculated values significantly differ from experimental values. Therefore, the effect of $\mathrm{Ni}$ powder will be evaluated only for $\mathrm{CF}$ content of $10 \mathrm{wt} \%$. Based on the additional contribution of Ni powder to the resistivity of the films, the parameter $X$ for the hybrid filler may be given as $X_{B}=X_{10}+\Delta X$, where $X_{10}$ is value calculated for the composite film with $\mathrm{CF}$ concentration of 10 $\mathrm{wt} \%$. Then, using Eq. (1) the ratio of the resistivity of $(10 \mathrm{CF}+$ 
Table 2. Values of calculated parameters in fiber contact model

\begin{tabular}{ccccccc}
\multicolumn{2}{c}{ CF content } & \multicolumn{2}{c}{ Parameter } & \multicolumn{3}{c}{ Resistivity ratio $^{\mathrm{a}}$} \\
\hline $\mathrm{wt} \%$ & $\mathrm{vol} \%$ & $\mathrm{~m}$ & $\mathrm{X}$ & $\rho_{5} / \rho_{10}$ & $\rho_{10} / \rho_{20}$ & $\rho_{5} / \rho_{20}$ \\
\hline 5 & 2.73 & 3.48 & 0.899 & & & \\
10 & 5.60 & 7.14 & 0.602 & 3.06 & 3.60 & 11.01 \\
20 & 11.77 & 15 & 0.352 & & & \\
\hline
\end{tabular}

CF: carbon fiber.

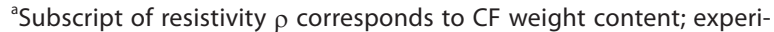
mental resistivity ratios are given in parentheses

$10 \mathrm{Ni})$ / $80 \mathrm{HDPE}$ film $\left(\rho_{\mathrm{B}}\right)$ to resistivity of $20 \mathrm{CF} / \mathrm{HDPE}$ film $\left(\rho_{20}\right), \rho_{\mathrm{B}} / \rho_{20}$, can be obtained as follows:

$$
\begin{aligned}
\frac{\rho_{B}}{\rho_{20}} & =\frac{X_{B} \phi_{20}}{X_{20} \phi_{10}}=\frac{\left(X_{10}+\Delta X\right) \phi_{20}}{X_{20} \phi_{10}} \\
& =\frac{X_{10} \phi_{20}}{X_{20} \phi_{10}}+\frac{\Delta X \phi_{20}}{X_{20} \phi_{10}}=\frac{\rho_{10}}{\rho_{20}}+\Delta
\end{aligned}
$$

From this, it follows that $\Delta$, the difference between the ratio $\rho_{\mathrm{B}} / \rho_{20}$ and the ratio $\rho_{10} / \rho_{20}$, can be expressed as:

$$
\Delta=\frac{\rho_{B}}{\rho_{20}}-\frac{\rho_{10}}{\rho_{20}}=\frac{\Delta X \phi_{20}}{X_{20} \phi_{10}}
$$

By rearranging Eq. (5), we obtain:

$$
\Delta X=\Delta \frac{X_{20} \phi_{10}}{\phi_{20}}
$$

After substituting the experimental value of the parameters in Eq. (6), we obtain $\Delta X=-0.0457$. The minus sign indicates that the addition of $\mathrm{Ni}$ powder decreases the parameter $X$ and, in turn, increases the number of contacts $m$. Using Eq. (2), the calculated increase of $m$ would be $\Delta m=0.91$. This means that the number of contacts for the $(10 \mathrm{CF}+10 \mathrm{Ni}) / 80 \mathrm{HDPE}$ composite film increased by $12.7 \%$ when compared to that of the 10 CF / 90 HDPE composite film without Ni powder. Thus, assuming the applicability of the fiber contact model to the composite films filled with hybrid filler, the main effect of Ni powder is the reduction of $\mathrm{CF}$ contact resistance in the composite film. As a result, the volume resistivity of the composite films filled with hybrid filler is higher than those filled with about the same CF content.

Tensile strengths of 32.5 and $22.5 \mathrm{MPa}$ were measured for the $10 \mathrm{CF} / 90 \mathrm{HDPE}$ and $(10 \mathrm{CF}+10 \mathrm{Ni}) / 80 \mathrm{HDPE}$ films, respectively, indicating that the addition of $\mathrm{Ni}$ powder resulted in a decrease of the tensile strength of the composite films, probably due to a rise in the number of defects in the polymer matrix and a reduction of the CF-HDPE bonding. Generation of defects in the structure can cause an increase of the coefficient of thermal expansion (CTE) in the film [22] and can be a main reason for the TCR change. The TCR of the composite films filled with hybrid filler increased when compared with the TCR of the composite films filled with CF only. The increase of TCR with increasing $\mathrm{Ni}$ powder in the hybrid filler (Fig. 2) was due to the reduction of the CF content and the decrease of the CF reinforcing effect in the polymer matrix, which leads to increases of the CTE and of TCR, simultaneously.

\section{Conclusion}

The effects of the amount of nickel powder in a Ni-CF hybrid filler system on the conductivity (resistivity) and TCR of filled HDPE were studied. The resistivity of the composite film at a given hybrid filler content of $20 \mathrm{wt} \%$ increased from 0.11 to $0.25 \Omega \cdot \mathrm{cm}$ with increasing Ni concentration, to $10 \mathrm{wt} \%$ in the hybrid filler. The insignificant increase indicated that the role of Ni powder is to improve the electrical contact between CFs, which is also equivalent to an increase of the extent of interfiber contacts in the CF conductive network. However, increasing the Ni concentration to $16 \mathrm{wt} \%$ causes a rapid increase the resistivity of about 4 times (to $1.04 \Omega \cdot \mathrm{cm}$ ); also, the resistivity of the composite film increased more than $10^{9} \Omega \cdot \mathrm{cm}$ at an $\mathrm{Ni}$ concentration of $20 \mathrm{wt} \%$, implying that the high concentration of $\mathrm{Ni}$ powder in the hybrid fillers was inefficient. Using the fiber contact model, it was shown that the addition of Ni powder in a concentration range lower than the critical one increases the electrical conductivity of the $\mathrm{CF}$ reinforced film, mainly due to the improvement of electrical contacts in the conductive network and reduction of the CF contact resistance. An increase of TCR with increasing amount of $\mathrm{Ni}$ powder in the hybrid filler was observed; this increase was attributed to the reduction of the CF content and the decrease of the CF reinforcing effect in the polymer matrix, which phenomena lead to increases of the CTE and TCR, simultaneously.

\section{Acknowledgements}

This work was financially supported by the Soft Innovative Materials Research Center of the Korea Institute of Science and Technology (KIST). This research was also kindly supported by a grant from the Fundamental R\&D Program for Technology of World Premier Materials funded by the Ministry of Knowledge Economy, Republic of Korea.

\section{References}

[1] Arjmand M, Mahmoodi M, Gelves GA, Park S, Sundararaj U. Electrical and electromagnetic interference shielding properties of flow-induced oriented carbon nanotubes in polycarbonate. Carbon, 49, 3430 (2011). http://dx.doi.org/10.1016/j.carbon.2011.04.039.

[2] Gelves GA, Al-Saleh MH, Sundararaj U. Highly electrically conductive and high performance EMI shielding nanowire/polymer nanocomposites by miscible mixing and precipitation. J Mater Chem, 21, 829 (2011). http://dx.doi.org/10.1039/C0JM02546A.

[3] Kim SH, Jang SH, Byun SW, Lee JY, Joo JS, Jeong SH, Park MJ. Electrical properties and EMI shielding characteristics of polypyrrole-nylon 6 composite fabrics. J Appl Polym Sci, 87, 1969 (2003). http://dx.doi.org/10.1002/app.11566.

[4] Yang Q, Wei S, Cheng G. Preparation of conductive polyaniline/ epoxy composite. Polym Compos, 27, 201 (2006). http://dx.doi org/10.1002/pc.20176.

[5] Immonen K, Nattinen K, Sarlin J, Hartikainen J. Conductive plastics with hybrid materials. J Appl Polym Sci, 114, 1494 (2009). http://dx.doi.org/10.1002/app.30767. 
[6] Zavickis J, Knite M, Podins G, Linarts A, Orlovs R. Polyisoprenenanostructured carbon composite-a soft alternative for pressure sensor application. Sensors Actuators A, 171, 38 (2011). http:// dx.doi.org/http://dx.doi.org/10.1016/j.sna.2011.05.035.

[7] Ciselli P, Lu L, Busfield JJC, Peijs T. Piezoresistive polymer composites based on EPDM and MWNTs for strain sensing applications. e-Polymers, 14 (2010).

[8] Chen L, Chen GH, Lu L. Piezoresistive behavior study on fingersensing silicone rubber/graphite nanosheet nanocomposites. Adv Funct Mater, 17, 898 (2007). http://dx.doi.org/10.1002/adfm. 200600519.

[9] Isaji S, Bin Y, Matsuo M. Electrical and self-heating properties of UHMWPE-EMMA-NiCF composite films. J Polym Sci B, 47, 1253 (2009). http://dx.doi.org/10.1002/polb.21722.

[10] Wang J, Guo W, Cheng S, Zhang Z. Structure and applications of $\mathrm{CB} /$ crystal fluoride resin alloy in self-regulated heating cables. J Appl Polym Sci, 88, 2664 (2003). http://dx.doi.org/10.1002/ app. 12078.

[11] Kim TA, Kim HS, Lee SS, Park M. Single-walled carbon nanotube/silicone rubber composites for compliant electrodes. Carbon, 50, 444 (2012). http://dx.doi.org/10.1016/j.carbon.2011.08.070.

[12] Park J, Lee A, Yim Y, Han E. Electrical and thermal properties of PEDOT:PSS films doped with carbon nanotubes. Synth Met, 161, 523 (2011). http://dx.doi.org/10.1016/j.synthmet.2011.01.006.

[13] Rathy I, Kuki A, Borda J, Deak G, Zsuga M, Marossy K, Keki S. Preparation and characterization of poly(vinyl chloride)-continuous carbon fiber composites. J Appl Polym Sci, 124, 190 (2012). http://dx.doi.org/10.1002/app.33617.

[14] Selzer R, Friedrich K. Mechanical properties and failure behaviour of carbon fibre-reinforced polymer composites under the influence of moisture. Composites A, 28, 595 (1997). http://dx.doi. org/10.1016/S1359-835X(96)00154-6.
[15] Balta Calleja FJ, Bayer RK, Ezquerra TA. Electrical conductivity of polyethylene-carbon-fibre composites mixed with carbon black. J Mater Sci, 23, 1411 (1988). http://dx.doi.org/10.1007/ BF01154609.

[16] Shen L, Wang FQ, Yang H, Meng QR. The combined effects of carbon black and carbon fiber on the electrical properties of composites based on polyethylene or polyethylene/polypropylene blend. Polym Test, 30, 442 (2011). http://dx.doi.org/10.1016/j. polymertesting.2011.03.007.

[17] Gokturk HS, Fiske TJ, Kalyon DM. Effects of particle shape and size distributions on the electrical and magnetic properties of nickel/polyethylene composites. J Appl Polym Sci, 50, 1891 (1993). http://dx.doi.org/10.1002/app.1993.070501105.

[18] Gokturk HS, Fiske TJ, Kalyon DM. Electric and magnetic properties of a thermoplastic elastomer incorporated with ferromagnetic powders. IEEE Trans Magn, 29, 4170 (1993). http://dx.doi org/10.1109/20.280866.

[19] Qin FX, Peng HX, Pankratov N, Phan MH, Panina LV, Ipatov M, Zhukova V, Zhukov A, Gonzalez J. Exceptional electromagnetic interference shielding properties of ferromagnetic microwires enabled polymer composites. J Appl Phys, 108, 044510 (2010). http://dx.doi.org/10.1063/1.3471816.

[20] Mironov VS, Park M, Kim J, Lim S, Choe C. Effect of sizing agent on the properties of carbon fiber/polyethylene composite film. J Mater Sci Lett, 20, 1211 (2001). http://dx.doi org/10.1023/A:1010918721998.

[21] Weber M, Kamal MR. Estimation of the volume resistivity of electrically conductive composites. Polym Compos, 18, 711 (1997) http://dx.doi.org/10.1002/pc.10324.

[22] Meyer J. Stability of polymer composites as positive-temperaturecoefficient resistors. Polym Eng Sci, 14, 706 (1974). http://dx.doi. org/10.1002/pen.760141009. 